\title{
Effect of Two Teaching Methods on Learning Outcomes Regarding Prevention of Cervical Cancer Among Married Women in Rural Areas of Kannur District, Kerala-A Pilot Study
}

\author{
Josephine Jacquline MaryNI ${ }^{1}$, Kashmir Kundapur ${ }^{2}$, Arya S Nighina, Somiya John $\mathrm{P}^{1}$, Soumya $\mathrm{SV}^{1}$ and \\ ViswamKrishnan ${ }^{3}$ \\ ${ }^{1}$ Principal, SIMET College of Nursing, Kerala \\ ${ }^{2}$ Professor in community Medicine-Nitte University, Kerala \\ ${ }^{3} I^{\text {nd }}$ year post basic BSc Nursing Students, SIMET College of Nursing, Kerala \\ *Corresponding author: Josephine Jacquline MaryNI, Department of Medical Surgical Nursing, SI MET College of Nursing, India

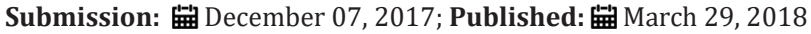

\begin{abstract}
Cervical cancer is the second most prevalent cancer among women worldwide and the fifth leading cause of cancer deaths. The study was conducted among married women who met the inclusion criteria in a selected rural areas at Kannur district to assess the effect of two teaching methods on learning outcomes regarding prevention of cervical cancer. Study adopted an experimental two group pre test post test design with a Quantitative research approach. Study was conducted in selected rural areas of Kannur district among married women in the age group 18-60 years. Sampling technique adopted for the study was simple random sampling with the sample size of 60 .
\end{abstract}

The study revealed that there is a marked improvement in the knowledge, attitude, practice and perceived barriers among the married women regarding prevention of cervical cancer after video assisted teaching rather than the self instructional module. Major findings of the study were; majority of the women belongs to the age group of 18-30years (50\%) and most of their age at marriage was 18-30 years (93.3\%), 56.7\% of women had college education and, $50 \%$ of women were housewives. In pre-test out of 30 samples 26(86.6\%) samples had inadequate knowledge before video assisted teaching were as in post test $19(63.3 \%)$ samples had adequate knowledge after VAT. In pretest out of 30 samples 25 (83.3\%) samples had inadequate knowledge before self instructional module were as in post test $3(10 \%)$ samples had adequate knowledge after SIM.

In pretest out of 30 samples 25(83.3\%) samples had positive attitude before video assisted teaching and in post test 30(100\%) had positive attitude after VAT. In pretest out of 30 samples 22(73.3\%) samples had positive attitude before self instructional module and in post test 29(96.6\%) had positive attitude after SIM. In pretest out of 30 samples 15(50\%) had good practice before video assisted teaching and in post test 22(73.3\%) had good practice after VAT. In pre-test out of 30 samples 15(50\%) samples had good practice before self instructional module and in post test 17(56.6\%) had good practice after SIM. Hence it can be inferred that video assisted teaching is more effective than self instructional module in increasing knowledge score among married women in rural area regarding prevention of cervical cancer.

Keyword: Cervical Cancer; Learning outcomes; VAT and self instructional module

\section{Introduction}

Cancer refers to a class of disease to which a cell or group of cells divide and replicate uncontrollably, intrude into adjacent cells and tissues and ultimately spread to other parts of the body than the location at which they arouse [2009]. Cervical cancer mostly affects women age between 18 to 45 , is linked to human papilloma virus, a sexually transmitted virus that can also cause genital warts. A pap smear or colposcopy can spot cervical cancer at an early stage and HPV [Human Papiloma Virus] vaccines have been developed [1,2].

\section{Background of the Study}

Cervical cancer is the second most prevalent cancer among women worldwide and the fifth leading cause of cancer deaths. A cross sectional study was conducted by Suryapriya Balan [3], to assess the Knowledge of cervical cancer screening among rural Indian women, 407 women aged 21-65 years in a selected village of Karnataka. Majority of the study population $(98.5 \%, 401)$ had poor knowledge regarding cervical cancer screening. There was no apparent difference in the mean and standard deviation of knowledge scores in the different categories of cervical cancer (2.49 \pm 1.665$)$, symptoms $(0.43 \pm 0.496)$, Pap smear test $(0.33 \pm 0.807)$ and screening guidelines $(0.51 \pm 0.742)$ (2013).

A cross-sectional study was conducted by Geeta V, to assess the awareness of cervical cancer among women of reproductive age group in urban slums of Karnataka. Total sample size was 
200. Result shows that about $7.5 \%$ of the respondents had heard about cervical cancer (2014). A cross sectional study conducted by Jansirani Siddharthar, to assess the knowledge [4], awareness and prevention of cervical cancer among women in tertiary care hospital in Puducherry. 400 women were recruited over three months for the study. The research findings showed that less than half of the study population $(178,44.5 \%)$ knew about cervical cancer. Less than one-fourth of the population knew about screening services for prevention of cervical cancer (2013).

\section{Need for the Study}

Cervical cancer is a sexually transmitted disease. It has been found that in many developed countries the annual incidence and prevalence of cervical cancer has decreased by $50 \%$ to $70 \%$ after introduction of population based screening. So if women in India undergo screening for cervical cancer [5], it is possible to detect cancer in early stages and thereby reducing mortality and morbidity. Improvement in living standard of women has resulted in a reduction in the incidence of cervical cancer. Regular cervical cytology examination by all women who have initiated sexual activity can prevent the occurrence of cervical cancer. Hence, the investigator decided to conduct a study on preventive aspects of cervical cancer among women of reproductive age in selected areas of Kerala [6].

\section{Objectives}

A. Compare the test scores on knowledge, attitude, practice and perceived barriers of women regarding cervical cancer before and after video assisted teaching.

B. Compare the test scores on knowledge, attitude, practice and perceived barriers of women regarding cervical cancer before and after the self-instructional module.

C. Determine the correlation between knowledge and attitude with the practice of women regarding cervical cancer.

D. Find out the association between knowledge, attitude, practice and perceived barriers with selected sociodemographic variables [7].

E. Identify the effect of pre and post test score on willingness of subjects to undergo Pap smear.

\section{Review of Literature}

A Large Prospective Cohort Study was conducted by Jissa V Thulaseedharan, to assess the Socio Demographic and Reproductive Risk Factors for Cervical Cancer in 113 local Panchayats from Rural India. 30,958 women were randomly selected for the study. The result shows that women of increasing age 95\%, having many pregnancies and no education were found to be at significantly increased risk of cervical cancer. These findings further stress the importance of formulating public health policies aimed at increasing awareness and implementation of cervical cancer screening programmes (2007).
An experimental study conducted by S Bharatha Sorubarani, to assess the effectiveness of video assisted teaching on prevention of cervical cancer among women in Milaganoor, Sivaganga district, Tamilnadu. Sample size of the study was 60 . Result shows that pre-test value is $31.076 \%$ and post-test value is $40.22 \%$ which shows that rural women lack in knowledge regarding cervical cancer and its prevention [8]. Video assisted teaching is the best method of intervention to create awareness among women in rural community (2013).

A cross sectional study was conducted by SuryapriyaBalan Thovarayi, to assess the Knowledge of cervical cancer screening among rural Indian women. 407 women aged 21-65 years in a randomly selected village of udupitaluk in Karnataka. Majority of the study population $(98.5 \%, 401)$ had poor knowledge regarding cervical cancer screening. There was no apparent difference in the mean and standard deviation of knowledge scores in the different categories of cervical cancer $(2.49 \pm 1.665)$, symptoms $(0.43 \pm 0.496)$, Pap smear test $(0.33 \pm 0.807)$ and screening guidelines $(0.51 \pm 0.742)$. There is very poor knowledge of cervical cancer screening among women (2013).

Another similar study was conducted by HN Harsha Kumar, to assess the knowledge and Screening for Cervical Cancer among Women attending the outpatient departments of teaching hospitals attached to Kasturba Medical College. A sample size of 83 was selected. Majority of the women have poor knowledge about cervical cancer (81.9\% [68/83]) and it's screening (85.5\% [71/83]). Only 6 out of 83 women had undergone screening (2012). Hence these findings made the researcher to conduct the study on imparting knowledge on preventive aspects of cervical cancer [9].

\section{Research Methodology}

The study was conducted among married women who met the inclusion criteria in a selected rural areas at Kannur district to assess the effect of two teaching methods on learning outcomes regarding prevention of cervical cancer. Study adopted an experimental two group pre test post test design with a Quantitative research approach. Study was conducted in a selected rural areas of Kannur district among married women in the age group of 18- 60 years comes under PHC and CHC. Sampling technique adopted for the study was simple random sampling with the sample size of 60 [10].

\section{Data Collection Process}

A prior formal permission obtained from the concerned Institutional authority. The purpose of the study was explained and consent was obtained from the subjects. The investigators recruited 60 samples as per the inclusion criteria and divided into two groups for VAT and the SIM. Each group served as control to other group. Structured questionnaire was used to assess the learning outcomes on knowledge, attitude, practices and perceived barriers among married women regarding prevention of cervical cancer. After the administration of self instructional module and video assisted teaching the post test was conducted after 7 days of educational interventions 


\section{Major Findings}

The study deals with analysis and interpretation of pre test and post test data on knowledge, attitude, practice and perceived barriers collected from 60 married women using structured questionnaire regarding the prevention of cervical cancer.

\section{A. Part I: Description of the demographic variables of} the respondents

The percentage distribution of respondents participated in the video assisted teaching according to their age shows that majority of the respondents $15(50 \%)$ were in the age group of 18-30 years. The percentage distribution of respondents participated in the self instructional module according to their age shows that majority of the respondents $12(40 \%)$ were in the age group of 18-30 years. The percentage distribution of respondents participated in the video assisted teaching according to their age at marriage shows that majority of the respondents $28(93.3 \%)$ were in the age group of 18-30 years, and none of the respondents age at marriage falls within 41-60 years. The percentage distribution of respondents participated in the self instructional module according to their age at marriage $29(96.7 \%)$.

In VAT group majority of the respondents $17(56.7 \%)$ had college education, and $2(6.7 \%)$ had primary education. Where as in SIM group majority of the respondents $14(46.7 \%)$ had college education, and $1(3.3 \%)$ had primary education.

B. Part II: Analysis of Pre Test and Post Test Score on Knowledge, Attitude, Practice and Perceived Barriers of Women Regarding Prevention of Cervical Cancer

The data presented in the Table $1 \&$ Table 2 shows that there is no effectiveness on perceived barriers of women regarding prevention of cervical cancer before and after video assisted teaching. But there is effectiveness on knowledge, attitude and practice of women regarding cervical cancer before and after video assisted teaching.

Table 1: Mean, standard deviation, standard error of pre test and post test score on knowledge, attitude, practice and perceived barriers of respondents before and after video assisted teaching.

\begin{tabular}{|c|c|c|c|c|c|c|}
\hline \multicolumn{7}{|c|}{ Paired Samples Statistics } \\
\hline Variables & Tests & Mean & Std & Std.Error Mean & $\mathbf{T}$ & Sig.(2tailed) \\
\hline \multirow{2}{*}{$\begin{array}{l}\text { Knowledge on } \\
\text { cervical cancer }\end{array}$} & Pre & 3.0667 & 1.10433 & 0.20162 & \multirow{2}{*}{-13.3092} & \multirow{2}{*}{0} \\
\hline & Post & 6.1667 & 1.18419 & 0.2162 & & \\
\hline \multirow{2}{*}{$\begin{array}{l}\text { Attitude towards } \\
\text { cervical cancer }\end{array}$} & Pre & 3.6792 & 0.51974 & 0.09489 & \multirow[b]{2}{*}{-2.56343} & \multirow[b]{2}{*}{0.016} \\
\hline & Post & 3.9542 & 0.37064 & 0.06767 & & \\
\hline \multirow{2}{*}{ Practice } & Pre & 1.4714 & 0.3604 & 0.02484 & \multirow{2}{*}{3.117451} & \multirow{2}{*}{0.004} \\
\hline & Post & 1.9524 & 0.21134 & 0.03858 & & \\
\hline \multirow{2}{*}{ Perceived barriers } & Pre & 0.0194 & 0.05217 & 0.00953 & \multirow{2}{*}{0.626013} & \multirow{2}{*}{0.536} \\
\hline & Post & 0.0139 & 0.03159 & 0.00577 & & \\
\hline
\end{tabular}

Table 2: Mean, standard deviation, standard error of pre test and post test score on knowledge, attitude, practice and perceived barriers of respondents before and after self instructional module.

\begin{tabular}{|c|c|c|c|c|c|c|}
\hline \multicolumn{7}{|c|}{ Paired Samples Statistics } \\
\hline Variables & Tests & Mean & Std. Deviation & Std.Error & t & Sig. \\
\hline \multirow{2}{*}{$\begin{array}{l}\text { Knowledge on } \\
\text { cervical cancer }\end{array}$} & Pre & 2.2 & 1.87819 & 0.34291 & \multirow{2}{*}{-6.45934} & \multirow{2}{*}{0} \\
\hline & Post & 4.7667 & 0.98902 & 0.18057 & & \\
\hline \multirow{2}{*}{$\begin{array}{l}\text { Attitude towards } \\
\text { cervical cancer }\end{array}$} & Pre & 3.5333 & 0.88445 & 0.16148 & \multirow{2}{*}{-2.52688} & \multirow{2}{*}{0.017219} \\
\hline & Post & 3.9667 & 0.40462 & 0.07387 & & \\
\hline \multirow{2}{*}{ Practice } & Pre & 1.4905 & 0.10399 & 0.01899 & \multirow{2}{*}{-0.39881} & \multirow{2}{*}{0.692955} \\
\hline & Post & 1.5048 & 0.16665 & 0.03043 & & \\
\hline \multirow{2}{*}{ Perceived barriers } & Pre & 0.0167 & 0.04035 & 0.00737 & \multirow{2}{*}{0} & \multirow{2}{*}{1} \\
\hline & Post & 0.0167 & 0.05085 & 0.00928 & & \\
\hline
\end{tabular}


The data presented in the Table 3 shows that there is no effectiveness on practice and perceived barriers of women regarding prevention of cervical cancer in before and after self instructional module. And there is an effectiveness on knowledge and attitude of women regarding cervical cancer in before and after self instructional module.

Table 3: Bivariate analysis of correlation of pre test between knowledge and attitude with the practice of respondents.

\begin{tabular}{|c|c|c|c|c|c|}
\hline \multicolumn{6}{|c|}{ Correlation of Pre test Score on Knowledge, Attitude with Practice } \\
\hline \multicolumn{3}{|c|}{ Groups } & Knowledge & Attitude & Practice \\
\hline \multirow{6}{*}{ VDO } & \multirow{2}{*}{ Knowledge } & Pearson Correlation & 1 & 0.241 & -0.069 \\
\hline & & Sig.(2-tailed) & - & 0.199 & 0.718 \\
\hline & \multirow{2}{*}{ Attitude } & Pearson Correlation & 0.241 & 1 & -0.33 \\
\hline & & Sig.(2-tailed) & 0.199 & - & 0.075 \\
\hline & \multirow[t]{2}{*}{ Practice } & Pearson Correlation & -0.069 & -0.33 & 1 \\
\hline & & Sig.(2-tailed) & 0.718 & 0.075 & - \\
\hline \multirow{6}{*}{ SIM } & \multirow{2}{*}{ Knowledge } & Pearson Correlation & 1 & $.586^{* *}$ & $-.393^{*}$ \\
\hline & & Sig.(2-tailed) & - & 0.001 & 0.031 \\
\hline & \multirow{2}{*}{ Attitude } & Pearson Correlation & $.586^{* *}$ & 1 & -0.117 \\
\hline & & Sig.(2-tailed) & 0.001 & - & 0.538 \\
\hline & \multirow{2}{*}{ Practice } & Pearson Correlation & $-.393 *$ & -0.117 & 1 \\
\hline & & Sig.(2-tailed) & 0.031 & 0.538 & - \\
\hline
\end{tabular}

Table 4: Grading of pre-test and post-test knowledge score of video assisted teaching.

\begin{tabular}{|c|c|c|c|c|c|c|}
\hline Area & Good $\mathbf{7 0 \%}$ & Percentage & $\begin{array}{c}\text { Moderate } \\
\mathbf{5 0 - 7 0} \%\end{array}$ & Percentage & Low <50\% & Percentage \\
\hline Pre-test & 0 & 0 & 4 & $13.30 \%$ & 26 & $86.60 \%$ \\
\hline Post-test & 19 & $63.30 \%$ & 7 & $23.30 \%$ & 4 & $13.30 \%$ \\
\hline
\end{tabular}

Part III: Correlation between knowledge and attitude with the practice of women regarding prevention of cervical cancer

(Table 4)

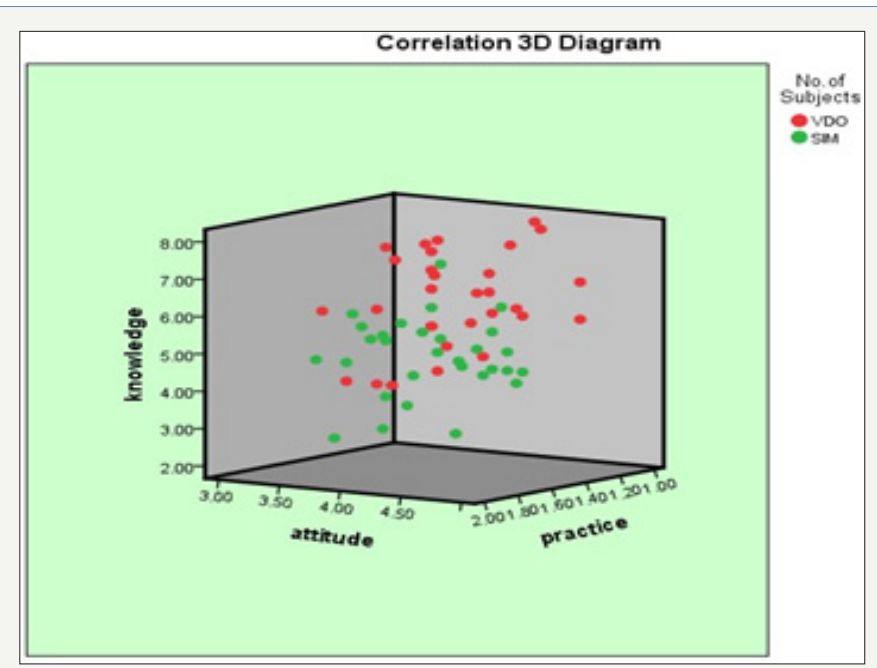

Figure $1: 3 \mathrm{D}$ diagram showing correlation of post-test on knowledge, attitude with practice.

Part IV: Effect of Pre and Post Test Scores on Willingness of Subjects to Undergo Pap Smear The data shows that 22(73.3\%) of respondents are willing to undergo pap smear test and $8(26.6 \%)$ of respondents are not willing to undergo pap smear test in video assisted teaching. In self instructional module 17(56.6\%) of respondents are willing to undergo pap smear test and 13(43.3\%) of respondents are not willing to undergo pap smear test (Figure 1).

In pretest out of 30 samples $26(86.6 \%)$ samples had inadequate knowledge before video assisted teaching were as in post test $19(63.3 \%)$ samples had adequate knowledge after VAT. In pretest out of 30 samples 25(83.3\%) samples had inadequate knowledge before self instructional module were as in post test $3(10 \%)$ samples had adequate knowledge after SIM.

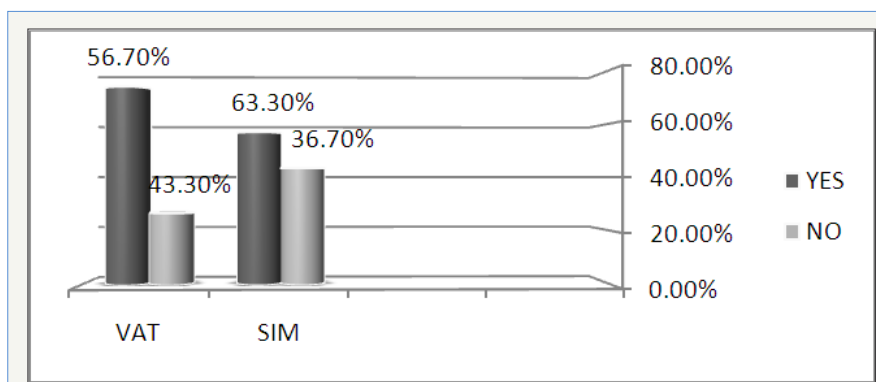

Figure 2: Bar diagram showing post-test score on willingness to undergo Pap smear test.

In pretest out of 30 samples $15(50 \%)$ had good practice before video assisted teaching and in post test 22(73.3\%) had good practice after VAT. In pretest out of 30 samples 15(50\%) samples had good practice before self instructional module and in post test $17(56.6 \%)$ had good practice after SIM (Figure $2 \& 3$ ). 


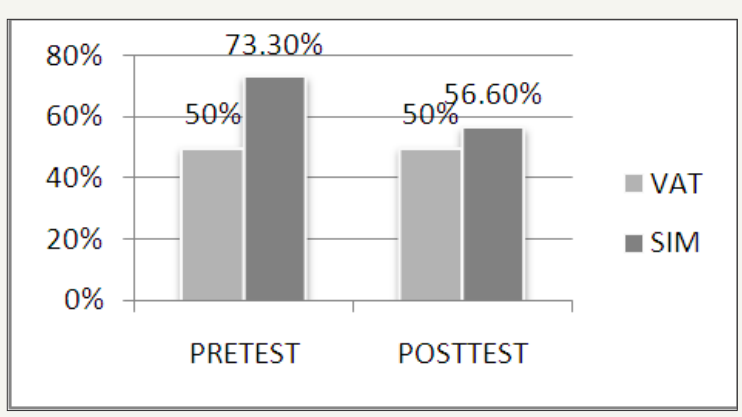

Figure 3 : Grading of pre-test and post-test practice score of video assisted teaching and self instructional module.

In pretest out of 30 samples $25(83.3 \%$ ) samples had positive attitude before video assisted teaching and in post test 30(100\%) had positive attitude after VAT. Where as in pretest for SIM out of 30 samples $22(73.3 \%)$ samples had positive attitude before and in post test 29(96.6\%) had positive attitude after administering SIM (Table 5 \& 6).

Table 5: Grading of pre-test and post-test knowledge score of self instructional module.

\begin{tabular}{|c|c|c|c|c|c|c|}
\hline Area & $\begin{array}{c}\text { Good } \\
\mathbf{7}\end{array}$ & $\begin{array}{c}\text { Perce } \\
\text {-ntage }\end{array}$ & $\begin{array}{c}\text { Moderate } \\
\mathbf{5 0 - 7 0 \%}\end{array}$ & $\begin{array}{c}\text { Percen } \\
\text {-tage }\end{array}$ & $\begin{array}{c}\text { Low } \\
\mathbf{< 5 0 \%}\end{array}$ & $\begin{array}{c}\text { Percen } \\
\text {-tage }\end{array}$ \\
\hline Pre-test & 0 & 0 & 5 & $16.60 \%$ & 25 & $83.30 \%$ \\
\hline $\begin{array}{c}\text { Post- } \\
\text { test }\end{array}$ & 3 & $10 \%$ & 19 & $63.30 \%$ & 8 & $26.60 \%$ \\
\hline
\end{tabular}

Table 6: Grading of pre-test and post-test attitude score of video assisted teaching and self instructional module.

\begin{tabular}{|c|c|c|c|c|}
\hline \multicolumn{4}{|c|}{ Attitude Score } \\
\hline \multirow{2}{*}{} & \multicolumn{2}{|c|}{ Pretest } & \multicolumn{2}{c|}{ Posttest } \\
\cline { 2 - 5 } & Frequency & Percentage & Frequency & Percentage \\
\hline VDO & 25 & $83.30 \%$ & 30 & $100 \%$ \\
\hline SIM & 22 & $73.30 \%$ & 29 & $96.60 \%$ \\
\hline
\end{tabular}

\section{Nursing Implications}

\section{Nursing practice}

The nursing personnel need to prepare instructional materials which should be simple, clear and understandable that can be studied at their own with other family members. Nursing personnel working in various units of hospitals will be able to find opportunities to teach and improve the knowledge regarding cervical cancer and its prevention.

\section{Nursing education}

The study has proved that improving the knowledge of married women brings about better awareness regarding prevention of cervical cancer. Nurses must be abreacting with new technologies, new approaches and techniques. Findings should be included in the nursing curriculum.

\section{Nursing administration}

Nursing administrators should take interest in motivating the nursing personnel to improve their professional knowledge and skill by attending hands on training to perform pap smears as a screening programme.

\section{Nursing research}

This study yield fruitful outcomes that are of great help in addressing arising problems. The nurse researcher may effectively use the result of these studies and develop clear knowledge on prevention of cervical cancer among married women by means of preventive and promotive aspects of cervical cancer.

\section{Conclusion}

Hence, this study proves that, comparatively the Video assisted teaching was much effective than the self instructional module on learning outcomes regarding prevention of cervical cancer among married women in rural areas of Kannur district.

\section{References}

1. Aswathy S, Quereshi MA, Kurian B, Leelamoni K (2012) Cervical cancer screening: Current knowledge \& practice among women in a rural population of Kerala. Indian J Med Res 136(2): 205-210.

2. Harsha Kumar H, Tanya S (2014) A Study on Knowledge and Screening for cervical Cancer among Women in Mangalore City. Ann Med Health Sci Res 4(5): 751-756.

3. Suryapriya Balan Thovarayi (2013) Knowledge of cervical cancer screening among rural Indian women: a cross sectional study. IOSRJNHS.

4. Balaiah Donta, Begum S, Nair S, Naik DD, Mali BN, et al. (2011) Awareness of Cervical Cancer among Couples in a Slum Area of Mumbai. Asian Pac J cancer prevention 13(10): 4901-4903.

5. World health organization (2006) Cervical cancer screening programme managerial guidelines. Geneva, Switzerland.

6. Dutta DC (2008) Textbook of Gynaecology ( $5^{\text {th }}$ edn), New central book agency, India.

7. Chintamani Lewis (2011) Medical surgical nursing. Reed Elsevier India private limited.

8. Anantharaman VV, S Sudharshini, A Chitra, (2013) A cross-sectional study on knowledge, attitude, and practice on cervical cancer and screening among female health care providers of Chennai Corporation. JAMS 2(4): 124-128.

9. Geetika Goel, Sumita Mehta, Shalini Rajaram, Neerja Goel (2013) Awareness about Human Papilloma Virus and its vaccine among medical students. Indian J community med 38(2): 92-94.

10. Siddharthar J, Rajkumar B, Deivasigamani K (2014) Knowledge, Awareness and Prevention of Cervical Cancer among Women Attending a Tertiary Care Hospital in Puducherry, India. J Clin Diagn Res 8(6): 0C01-0C03. 
Creative Commons Attribution 4.0 International License

For possible submissions Click Here

Submit Article

\section{COJNH $\mid \begin{gathered}\text { NuJsing \& } \\ \text { Healthicare }\end{gathered}$ \\ COJ Nursing \& Healthcare \\ Benefits of Publishing with us}

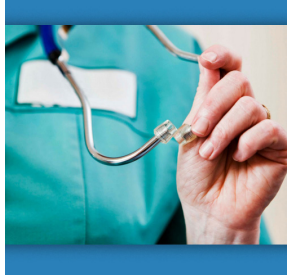

- High-level peer review and editorial services

- Freely accessible online immediately upon publication

- Authors retain the copyright to their work

- Licensing it under a Creative Commons license

- Visibility through different online platforms 